\title{
Formulation and development of metformin-loaded microspheres using Khaya senegalensis (Meliaceae) gum as co-polymer
}

Chukwuebuka H. Ozoude, Chukwuemeka P. Azubuike* (D, Modupe O. Ologunagba, Sejoro S. Tonuewa and Cecilia I. Igwilo

\begin{abstract}
Background: Khaya gum is a bark exudate from Khaya senegalensis (Maliaecae) that has drug carrier potential. This study aimed to formulate and comparatively evaluate metformin-loaded microspheres using blends of khaya gum and sodium alginate. Khaya gum was extracted and subjected to preformulation studies using established protocols while three formulations (FA; FB and FC) of metformin ( $1 \% \mathrm{w} / \mathrm{v}$ )-loaded microspheres were prepared by the ionic gelation method using 5\% zinc chloride solution as the cross-linker. The formulations contained $2 \% \mathrm{w} / \mathrm{v}$ blends of khaya gum and sodium alginate in the ratios of 2:3, 9:11, and 1:1, respectively. The microspheres were evaluated by scanning electron microscopy, Fourier transform-infrared spectroscopy, differential scanning calorimetry, entrapment efficiency, swelling index, and in vitro release studies.

Results: Yield of $28.48 \%$, pH of $4.00 \pm 0.05$, moisture content (14.59\% \pm 0.50 ), and fair flow properties (Carr's index $23.68 \pm 1.91$ and Hausner's ratio $1.31 \pm 0.03$ ) of the khaya gum were obtained. FTIR analyses showed no significant interaction between pure metformin hydrochloride with excipients. Discrete spherical microspheres with sizes ranging from 1200 to $1420 \mu \mathrm{m}$ were obtained. Drug entrapment efficiency of the microspheres ranged from 65.6 to $81.5 \%$. The release of the drug from microspheres was sustained for the $9 \mathrm{~h}$ of the study as the cumulative release was 62\% (FA), 73\% (FB), and 80\% (FC). The release kinetics followed Korsmeyer-Peppas model with super case-ll transport mechanism.

Conclusion: Blends of Khaya senegalensis gum and sodium alginate are promising polymer combination for the preparation of controlled-release formulations. The blend of the khaya gum and sodium alginate produced microspheres with controlled release properties. However, the formulation containing 2:3 ratio of khaya gum and sodium alginate respectively produced microspheres with comparable controlled release profiles to the commercial brand metformin tablet.
\end{abstract}

Keywords: Khaya senegalensis gum, Microspheres, Metformin, Ionic gelation, Controlled release

\footnotetext{
* Correspondence: cazubuike@unilag.edu.ng

Department of Pharmaceutics and Pharmaceutical Technology, Faculty of

Pharmacy, University of Lagos, College of Medicine Campus, Surulere, Lagos,

Nigeria
}

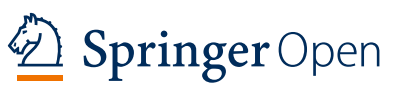

(c) The Author(s). 2020 Open Access This article is licensed under a Creative Commons Attribution 4.0 International License, which permits use, sharing, adaptation, distribution and reproduction in any medium or format, as long as you give appropriate credit to the original author(s) and the source, provide a link to the Creative Commons licence, and indicate if changes were made. The images or other third party material in this article are included in the article's Creative Commons licence, unless indicated otherwise in a credit line to the material. If material is not included in the article's Creative Commons licence and your intended use is not permitted by statutory regulation or exceeds the permitted use, you will need to obtain permission directly from the copyright holder. To view a copy of this licence, visit http://creativecommons.org/licenses/by/4.0/. 


\section{Background}

Natural polymers are attractive, primarily because they are inexpensive, biodegradable, biocompatible, readily available, and non-toxic [1, 2]. These polymers have functional groups that make them able to be chemically modified to obtain products with desirable physicochemical properties. These qualities of natural polymers have attracted researches towards their widespread applications.

Khaya gum is obtained as exudates from the incised trunks of trees from the Genus, Khaya including the species: Khaya grandifolia, Khaya senegalensis, Khaya ivorensis (Family: Meliaceae) [3]. Khaya gum has been evaluated for several industrial applications such as binder [4], film coating [5], disintegrant [6], controlled release polymer [7].

Metformin (dimethylbiguanide) is majorly used in the management of type 2 diabetes mellitus. It acts by decreasing peripheral insulin resistance and hepatic glucose output. Metformin could be used in the management and treatment of steatohepatitis $[8,9]$, polycystic ovarian syndrome [10]. With absolute oral bioavailability of 40-60\% and a mean plasma elimination half-life of $6 \mathrm{~h}$, the frequency of administration is two to three times daily [11]. Controlled release formulations are needed to prolong its duration of action and to improve patient compliance.

Microspheres are microparticles made up of a polymeric matrix containing the drug which is dispersed at macroscopic or molecular level $[12,13]$. Microspheres have the following advantages: sustained release properties, higher concentration of the active pharmaceutical ingredient at the target tissue, and increased bioavailability.

Synthetic polymers used in the production of marketed sustained release metformin tablets increase the cost of these medicines especially in low- and middle-income economies. Therefore, utilising readily available natural polymers will reduce cost and provide easier access to essential medicines. Although, different studies have been carried out on several industrial applications of Khaya senegalensis gum and other related gums [4-7], to the best of the authors' knowledge, there is no report on the use of khaya gum as a copolymer in the formulation of metformin-loaded microspheres.

This research aims to develop metformin-loaded microspheres using Khaya senegalensis gum as co-polymer by employing ionic gelation technique and to modulate release of the drug thereby reducing the frequency of its administration.

\section{Materials}

Khaya senegalensis plant was identified and authenticated. Voucher specimen number LUH 8582 was assigned and sample was deposited in the herbarium. Metformin hydrochloride powder (IOL Chemicals and
Pharmaceuticals, India), sodium alginate (Loba Chemie, India), zinc chloride (Shanghai Chemex, China), absolute ethanol (BDH, Poole, England), chloroform (May and Baker reagent, England), and diethyl ether (Fisher Scientific, UK) were used in the study. All other reagents used were of analytical grade.

\section{Methods}

\section{Extraction and purification of Khaya senegalensis gum}

The method of Ofori-Kwakye et al. [14] was used in the extraction of the khaya gum. Briefly, one kilogram of dried crude Khaya senegalensis exudate was reduced and macerated in chloroform-water double strength and allowed to stand for $120 \mathrm{~h}$ with intermittent stirring. The gum mucilage was then strained with a muslin cloth to remove any insoluble impurities. Absolute ethanol was used to precipitate the mucilage. The mucilage was then collected and washed twice with diethyl ether and dried in hot air oven (Uniscope SM9053, England) at 40 ${ }^{\circ} \mathrm{C}$ for $24 \mathrm{~h}$. The extracted gum was dried at $40{ }^{\circ} \mathrm{C}$ for $24 \mathrm{~h}$. The dried gum was then pulverized using pestle and mortar and the powdered gum was passed through a sieve with mesh size of $210 \mu \mathrm{m}$. Thereafter, it was stored in an air-tight container until needed.

\section{Characterization of gum sample \\ Moisture content}

The moisture content of the gum sample was determined using a moisture analyser (Sartorius AG, Germany). Two grams of the gum powder was placed into the moisture balance and evenly spread on the tray. The readings were recorded at $15 \mathrm{~min}$.

\section{pH}

A $5.0 \% \mathrm{w} / \mathrm{v}$ dispersion of the gum powder was made with distilled water and the $\mathrm{pH}$ measured using a $\mathrm{pH}$ meter (Hanna instruments, USA).

\section{Ash value}

A $2 \mathrm{~g}$ weight of gum powder sample was poured into a nickel crucible which was initially heated at $105{ }^{\circ} \mathrm{C}$ in a furnace (Carbolite, Germany) to a constant weight. The temperature was then increased to $600{ }^{\circ} \mathrm{C}$ and heated for $6 \mathrm{~h}$. The sample temperature was allowed to cool to $100{ }^{\circ} \mathrm{C}$ and removed from the furnace, cooled in a desiccator over silica gel and reweighed using an analytical balance (Adventurer-Pro, Ohaus, USA). The weight of the residues (carbon-free ash) was determined and expressed as percentage of the initial sample.

For determination of the acid-insoluble ash content of the gum sample, the ash obtained from the above experiment was boiled with $25 \mathrm{~mL}$ of $2 \mathrm{M} \mathrm{HCl}$ for $5 \mathrm{~min}$. The insoluble residue was separated by centrifugation at $2000 \mathrm{rpm}$ for $10 \mathrm{~min}$ using a centrifuge (Thermo 
Scientific, Germany). The sediment obtained was resuspended in hot water and evaporated to dryness in a tarred crucible. The weight of the residue was expressed as a percentage of the initial weight of the sample.

\section{Phytochemical analysis}

Phytochemical analyses were carried out to test for the presence of secondary plant metabolites in the gum powder. Secondary metabolites are various chemical compounds produced by plants from the materials derived from primary metabolites. Molisch's test, Fehling's test, frothing test, lead acetate test, ferric chloride test, Shinoda test, Keller-Kiliani test, Borntrager's test, Salkowski's test, Liebermann-Burchard test, and Dragendorff's test were carried out using methods reported in previous studies to determine the presence of carbohydrates, reducing sugar, saponin, phenolic compounds, tannin, flavonoid, cardiac glycoside, anthraquinone, steroid, terpenoid, and alkaloid, respectively $[15,16]$.

\section{Elemental analysis}

Chromium $(\mathrm{Cr})$, cadmium $(\mathrm{Cd})$, copper $(\mathrm{Cu})$, lead $(\mathrm{Pb})$, nickel $(\mathrm{Ni})$, and cobalt $(\mathrm{Co})$ contents in the gum sample were determined using an Atomic Absorption Spectrometer (iCE 3000, Thermo Fisher). Five grams of oven dried samples were weighed into a crucible and placed in an incinerator at $600{ }^{\circ} \mathrm{C}$ and left to ash for $2 \mathrm{~h}$ and then cooled to $105{ }^{\circ} \mathrm{C}$ and the gum powder weighed. This process was repeated until a constant weight was obtained. The ashed samples $(0.5 \mathrm{~g})$ were weighed and transferred into the digestion tube. The ashed sample was mixed in the digestion tube with $5 \mathrm{~mL}$ each of distilled water, $1 \mathrm{M}$ perchloric acid and concentrated $\mathrm{HNO}_{3}$. The contents were digested on a heating mantle and the temperature was set at $150{ }^{\circ} \mathrm{C}$ for $120 \mathrm{~min}$ followed by the addition of $1 \mathrm{~mL}$ of $2 \mathrm{M} \mathrm{H}_{2} \mathrm{SO}_{4}$. Distilled water was added to the tube to make up to the mark, mixed, and filtered. The elements were determined by using an atomic absorption spectrophotometer (AAS) at an appropriate wavelength, temperature and lamp-current for the different elements.

\section{Micromeritics and rheological properties}

The bulk density, tapped density, Carr's index, and Hausner's ratio of the gum powder were determined according to the methods described by Azubuike et al. [17].

The viscosity of the gum powder was determined using a digital viscometer (DV-E, China). The viscosity values of $2 \%, 5 \%$, and $10 \% \mathrm{w} / \mathrm{v}$ aqueous dispersion of the gum were determined at $50 \mathrm{rpm}$ and $25{ }^{\circ} \mathrm{C}$. The swelling index of khaya gum was determined using the method employed by Ologunagba et al. [18].
Fourier-transform infrared spectroscopy (FTIR) analysis A $5 \mathrm{mg}$ quantity of khaya gum sample, metformin, and metformin-loaded microspheres were individually blended with $50 \mathrm{mg}$ of solid $\mathrm{KBr}$ and compressed into discs. The scanned range was from 500 to $4000 \mathrm{~cm}^{-1}$ in FTIR spectroscopy (Cary 630, Agilent Technologies, USA) under dry air at room temperature.

\section{Differential scanning calorimetry (DSC)}

The thermal behaviour of the gum powder was determined using differential scanning calorimeter (Mettler Toledo, USA) as described by Sindhu and Khatkar [19]. The gum powder $(6 \mathrm{mg})$ was weighed into an aluminum pan. The pan was hermetically sealed and equilibrated at room temperature for $1 \mathrm{~h}$, then heated at the rate of 10 ${ }^{\circ} \mathrm{C} /$ min from $30{ }^{\circ} \mathrm{C}$ to $250{ }^{\circ} \mathrm{C}$ with an empty-sealed pan as a reference. The DSC studies were also carried out for the pure metformin powder and the different formulations of the microspheres.

\section{Scanning electron microscopy (SEM)}

The granule morphology of the gum powder was observed in a scanning electron microscope (Pro X, The Netherlands). The gum powder was mixed with ethanol to obtain a $1 \%$ suspension. The suspension (one drop) was then smeared on aluminium stub with double-sided adhesive tape and the sample gum powder was coated with gold powder to avoid charging under the electron beam when the acetone has volatilized. An accelerating potential $(15 \mathrm{kV})$ was used during micrography [20].

\section{Preparation of metformin hydrochloride microspheres}

Polymer blends \{khaya gum:sodium alginate (2:3, 9:11, and 1:1) respectively\} consisting of the different ratios of khaya gum and sodium alginate were used. The choice of the ratio blends of the polymers were based on preformulation studies carried out. Microspheres embedded with metformin were prepared by the ionic gelation technique as described by Odeku et al. [21]. Briefly, appropriate quantities of metformin $(2 \% \mathrm{w} / \mathrm{v})$ were added and stirred continuously until a dispersion was obtained (2:1 ratio of polymer and drug respectively). The resulting dispersion was extruded into zinc chloride solution $(5 \% \mathrm{w} / \mathrm{v})$ using a $5 \mathrm{~mL}$ hypodermic syringe with a $23 \mathrm{G}$ needle at a dropping rate of $2 \mathrm{~mL} / \mathrm{min}$ and stirring speed of $300 \mathrm{rpm}$. The formed microspheres were allowed $30 \mathrm{~min}$ curing time and then left standing for $1 \mathrm{~h}$ to allow further cross-linking. The microspheres were collected by decantation, washed with distilled water, and then dried for $18 \mathrm{~h}$ in hot air oven at $40{ }^{\circ} \mathrm{C}$. The microspheres were then stored in airtight containers until needed. 


\section{Characterization of microspheres Size distribution of microspheres}

The sizes of microspheres were determined using an optical microscope (Leica, Germany) fitted with an ocular micrometer. The mean diameter reported was obtained from a total of more than 100 microspheres.

\section{Morphology of microspheres}

The morphology of the microspheres was analysed by scanning electron microscopy. The microspheres were dusted onto double sided tape on an aluminium stub and coated with gold using a cold sputter coater to a thickness of $400 \AA$ and then imaged using a $15 \mathrm{kV}$ electron beam. Photographs were taken within a range of 190-250 magnifications [22].

\section{Swelling index}

A $100 \mathrm{mg}$ quantity of microspheres was soaked in 20 $\mathrm{mL}$ of phosphate buffer, $\mathrm{pH} 6.8$ for $3 \mathrm{~h}$. After the $3 \mathrm{~h}$, the microspheres were then removed and excess buffer was wiped using a dry filter paper and their final weights were determined. Swelling index was calculated by using equation (1).

$$
\begin{aligned}
\text { swelling index }(\%)= & \frac{\text { change in weight }(\mathrm{mg})}{\text { original weight }(\mathrm{mg})} \\
& \times 100
\end{aligned}
$$

\section{Entrapment efficiency}

Appropriate quantity of drug-loaded microspheres was crushed in a glass mortar with a pestle, weighed to obtain $100 \mathrm{mg}$ (equivalent to $50 \mathrm{mg}$ of metformin) and then suspended in $50 \mathrm{~mL}$ of phosphate buffer, $\mathrm{pH} 6.8$. After $24 \mathrm{~h}$, the solution was filtered and the filtrate was appropriately diluted with phosphate buffer, $\mathrm{pH} 6.8$ and analysed using UV spectrophotometer (Biomate 3, USA) at $233 \mathrm{~nm}$. The drug entrapment efficiency (E) was then calculated using equation (2).

Table 1 Physicochemical and pharmacopoeial properties of Khaya senegalensis gum

\begin{tabular}{ll}
\hline Parameter & Result \\
\hline Yield (\%) & 28.48 \\
Colour & Brown \\
Odour & Characteristic odour \\
Taste & Slightly bland \\
Texture & Slightly gritty \\
Moisture content (\%) & $14.59 \pm 0.50$ \\
pH & $4.00 \pm 0.05$ \\
Total ash (\% w/w) & $5.25 \pm 0.14$ \\
Acid insoluble ash (\% w/w) & $2.08 \pm 0.09$ \\
\hline
\end{tabular}

Table 2 Elemental analysis of Khaya senegalensis gum powder

\begin{tabular}{ll}
\hline Metal & Content (ppm) \pm SD \\
\hline Chromium $(\mathrm{Cr})$ & $0.060 \pm 0.008$ \\
Cadmium $(\mathrm{Cd})$ & Not detected \\
Copper $(\mathrm{Cu})$ & $0.178 \pm 0.062$ \\
Lead $(\mathrm{Pb})$ & $0.009 \pm 0.006$ \\
Nickel $(\mathrm{Ni})$ & $0.024 \pm 0.008$ \\
Cobalt $(\mathrm{Co})$ & $0.018 \pm 0.004$ \\
\hline
\end{tabular}

$$
E(\%)=\frac{\text { practical drug content }}{\text { theoretical drug content }} \times 100
$$

\section{In vitro dissolution studies and kinetic modelling of release profiles}

The in vitro dissolution studies were carried out using the basket method USP type II rotated at $50 \mathrm{rpm}$ in 900 $\mathrm{mL}$ of phosphate buffer, $\mathrm{pH} 6.8$, maintained at $37 \pm 0.5$ ${ }^{\circ} \mathrm{C}$. The microspheres equivalent to $500 \mathrm{mg}$ of metformin was placed in the dissolution medium. Samples (5 $\mathrm{mL}$ ) were withdrawn at $0,30 \mathrm{~min}$ and then at $1 \mathrm{~h}$ intervals for $9 \mathrm{~h}$ and replaced each time with equal amounts of fresh medium. The samples withdrawn were filtered through a 0.45-micron membrane filter (Nunc, New Delhi, India). The amount of metformin released was determined after suitable dilution at wavelength of 233 nm, using a UV spectrophotometer (Biomate 3, USA). Dissolution test was also carried out using the same conditions for a sustained release marketed brand of metformin tablets (Panfor SR 500 mg, Mega Lifesciences Pty. Ltd., Thailand).

Kinetic modelling of the release data for the three microspheres formulations was carried out by fitting to different kinetic equations. The results of drug release from the microsphere formulations was fitted into drug release kinetic models-zero order, first order, Higuchi, and Korsmeyer-Peppas. The model of best fit was identified by comparing the values of correlation coefficients.

\section{Statistical analysis}

All the tests were carried out in triplicates. All the values were expressed as mean \pm standard deviation (SD).

Table 3 Micromeritics and rheological properties of Khaya senegalensis gum powder

\begin{tabular}{ll}
\hline Parameter & Results \pm SD \\
\hline Bulk density $(\mathrm{g} / \mathrm{mL})$ & $0.57 \pm 0.01$ \\
Tapped density $(\mathrm{g} / \mathrm{mL})$ & $0.75 \pm 0.01$ \\
Angle of repose $\left(^{\circ}\right)$ & $34.72 \pm 0.97$ \\
Carr's index & $23.68 \pm 1.91$ \\
Hausner's ratio & $1.31 \pm 0.03$ \\
Swelling index & $3.41 \pm 0.01$ \\
\hline
\end{tabular}




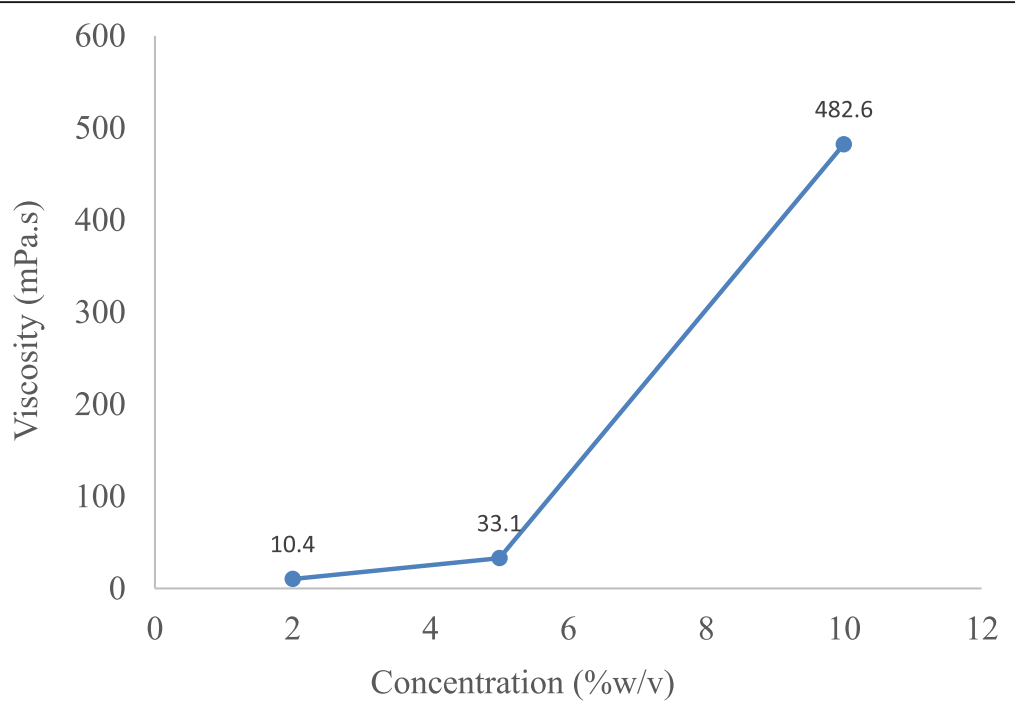

Fig. 1 Viscosities of different concentrations of Khaya senegalensis gum

Differences with $p<0.05$ were considered statistically significant. GraphPad Prism-7 software (GraphPad Software Inc., USA) was used for statistical analysis.

\section{Results}

Physicochemical and pharmacopoeial characterization of gum sample

Physicochemical and pharmacopoeial properties of Khaya senegalensis gum is presented in Table 1 . The $\mathrm{pH}$ of khaya gum $(4.00 \pm 0.05)$ was slightly higher than the one $(3.38 \pm 0.00)$ reported by Olorunsola et al. [23]. The moisture content reported for the khaya gum was within the moisture content limit $(15.0 \% \mathrm{w} / \mathrm{v})$ for natural gums [24]. The total ash content $(\% \mathrm{w} / \mathrm{w})$ was $5.25 \pm 0.14$. The allowed limit according to the British Pharmacopoeia [25] is $4.00 \% \mathrm{w} / \mathrm{w}$. This implies the presence of extraneous materials and impurities. Total ash content of Khaya senegalensis gum was lower $(3.00 \pm 0.15)$ in the findings of Akin-Ajani et al. [26].

Phytochemical screening showed that there was absence of some secondary plant metabolites in the gum powder, namely alkaloids, tannins, saponins, flavonoids, and amino acids. However, the gum sample contained

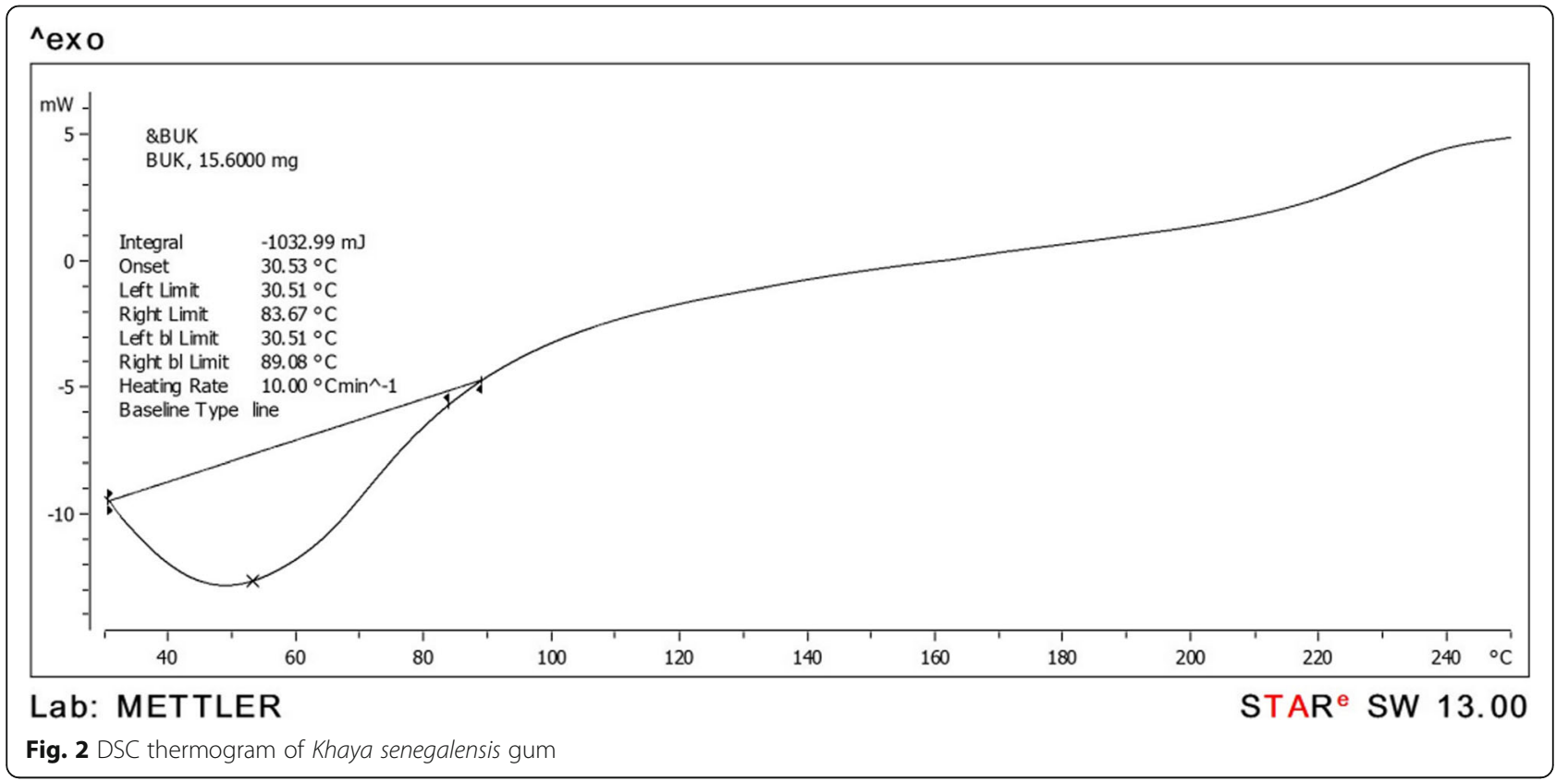


reducing sugars and trace of anthraquinones. The presence of carbohydrates and reducing sugars implies the presence of chains of monosaccharides and polysaccharides. Secondary metabolites are various chemical compounds produced by plants from the materials derived from primary metabolites. These phytoconstituents have bioactivities. It was therefore pertinent that this was investigated for this gum which was used in the study as a sustained release carrier. Gums are expected not to have these phytoconstituents except monosaccharides/reducing sugars (carbohydrates) and hence inert and biodegradable. The reported trace amount of anthraquinone observed might be due to parts of Khaya bark which was not totally eliminated by the extraction process used.

Table 2 represents the elemental composition of the Khaya senegalensis gum for polyvalent and heavy metals. The values obtained for copper, chromium, nickel, and lead were found to be within the USP limit for heavy metals content in oral drug products [27].

\section{Micromeritics and rheological properties}

As shown in Table 3, the bulk and tapped densities $(\mathrm{g} / \mathrm{mL})$ of the gum powder were $0.57 \pm 0.01$ and $0.75 \pm 0.01$, respectively. The Carr's index was $23.68 \pm 1.91$. Carr's index values from 23 to 35 have been classified to have poor flow [28]. Hausner's ratio obtained from the experiment was $1.31 \pm 0.03$. Hausner's ratio from 1.26 to 1.34 has passable flow character [28].

As seen in Table 3, the swelling index of the gum powder was $3.41 \pm 0.01$. Khaya senegalensis gum is hydrophilic and it can hydrate in water to form a gel.
The swelling index of a gum $(3.41 \pm 0.01)$ demonstrates its hydrophilic nature and its ability to swell into a gel in an aqueous medium [18].

As shown in Fig. 1, the viscosity of the gum sample obtained at 2,5 and $10 \% \mathrm{w} / \mathrm{v}$ were $10.4 \pm 0.79,33.1 \pm$ 0.86 , and $482.6 \pm 1.96 \mathrm{mPaS}$, respectively. This showed that the viscosity of gum increased as the concentration of gum dispersions increased from 2 to $10 \% \mathrm{w} / \mathrm{v}$.

\section{Differential scanning calorimetry (DSC)}

The thermal behaviour of Khaya senegalensis gum as represented in Fig. 2 showed that the gum had an onset temperature of $30.53{ }^{\circ} \mathrm{C}$, peak temperature of approximately $53.00{ }^{\circ} \mathrm{C}$, an endset temperature of $89.08{ }^{\circ} \mathrm{C}$, and an enthalpy change of $1032.99 \mathrm{~J} / \mathrm{g}$. The thermogram signifies that the gum sample could be stable at temperatures as high as $250{ }^{\circ} \mathrm{C}$ since there was no evidence of degradation [23].

\section{Scanning electron micrograph (SEM)}

The SEM of the extracted gum powder is represented in Fig. 3. The shape and surface characteristics of the particles were generally granular and rough. Khaya senegalensis gum showed irregularly shaped particle. It thus revealed the amorphous nature of the gum sample.

\section{Fourier transform-infrared spectroscopy (FTIR) study}

The stacked FTIR spectra of extracted Khaya senegalensis gum powder, pure metformin, and metformin-loaded microspheres is presented in Fig. 4.

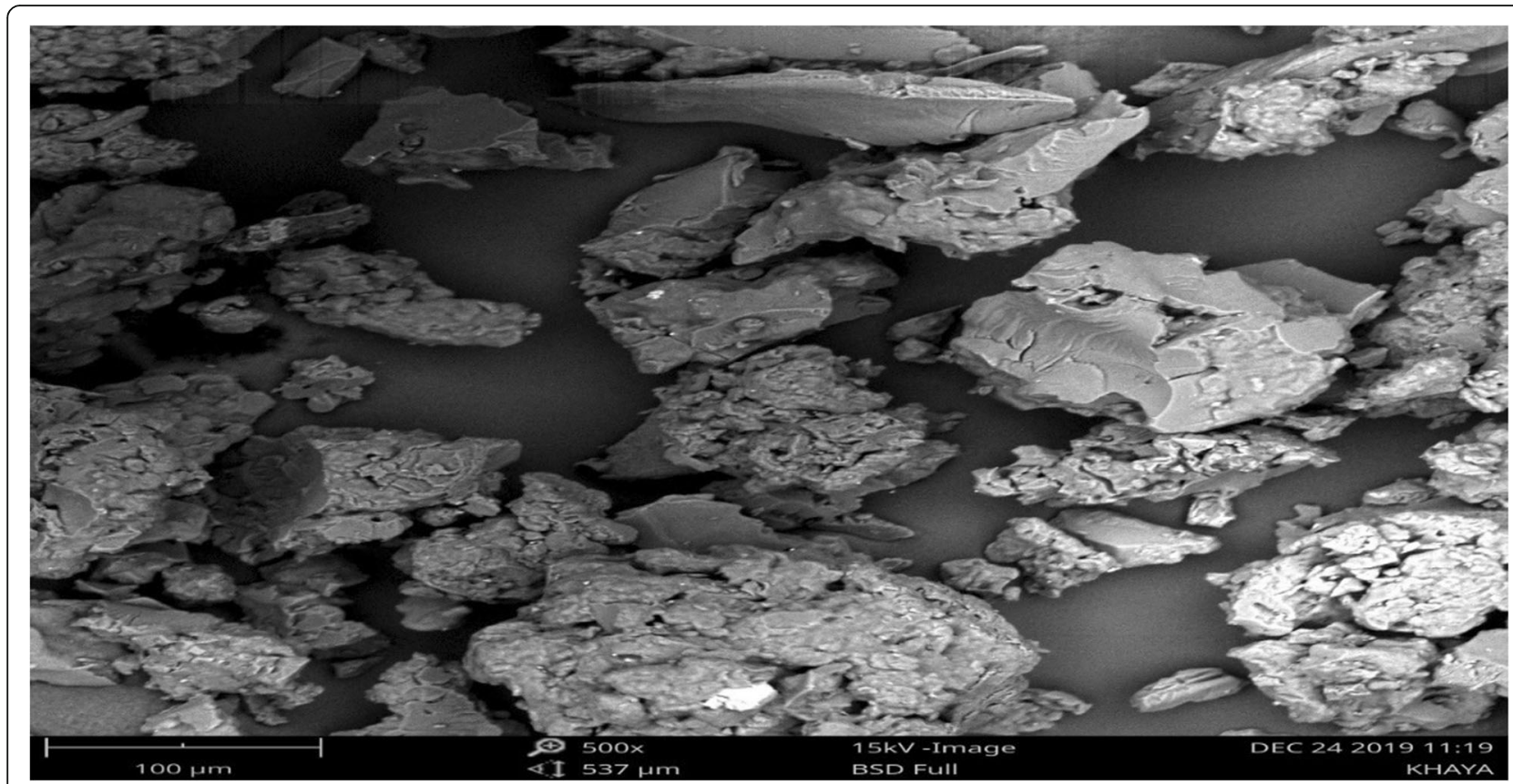

Fig. 3 SEM micrograph of Khaya senegalensis gum 

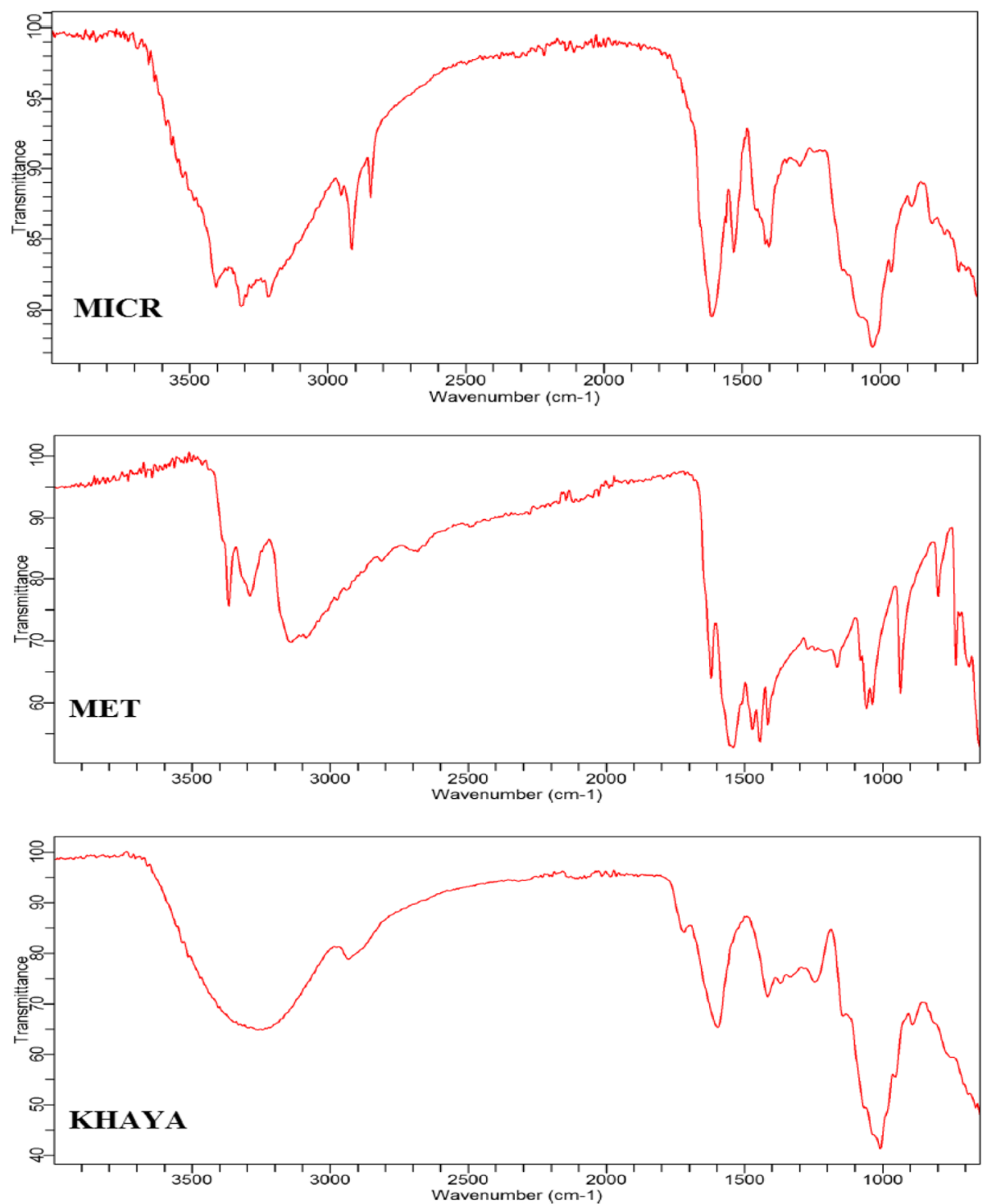

Fig. 4 Stacked FTIR spectra of Khaya senegalensis gum (KHAYA), pure metformin powder (MET), and microsphere (MICR)

The FTIR spectrum for khaya gum highlights some major bands and peaks. The peak at $894.6 \mathrm{~cm}^{-1}$ could be assigned to aromatic $\mathrm{C}-\mathrm{H}$ bending vibration while that at $2937.1 \mathrm{~cm}^{-1}$ could be attributed to $\mathrm{C}-\mathrm{H}$ stretching vibrations in the substituted aromatic hydrocarbon. The peaks at $1371.7 \mathrm{~cm}^{-1}$ and $1416.4 \mathrm{~cm}^{-1}$ could be assigned to O$\mathrm{H}$ bending of aromatic alcohol and carboxylic acids. The peak at $1718.3 \mathrm{~cm}^{-1}$ could be assigned to $\mathrm{C}=\mathrm{O}$ stretching of ether, unsaturated ester while that of $3246 \mathrm{~cm}^{-1}$ could be assigned to $\mathrm{O}-\mathrm{H}$ stretching of carboxylic acid.

\section{Physicochemical properties of microspheres}

The data for physicochemical properties of the metformin-loaded microspheres are presented in Table 4. The mean particle sizes of the microspheres $(\mu \mathrm{m})$ ranged from $1200.7 \pm 21.6$ to $1420.5 \pm$ 9.8. The SEM

Table 4 Physicochemical properties of microspheres

\begin{tabular}{lllll}
\hline Formulation code & Polymer blend khaya:sodium alginate (\%) & Microsphere size $(\boldsymbol{\mu m})$ & Swelling index (\%) & Entrapment efficiency (\%) \\
\hline FA & $2: 3$ & $1360.2 \pm 10.7$ & $32.80 \pm 2.67$ & $65.6 \pm 0.45$ \\
FB & $9: 11$ & $1200.7 \pm 21.6$ & $61.33 \pm 6.30$ & $78.6 \pm 1.32$ \\
FC & $1: 1$ & $1420.5 \pm 9.8$ & $74.27 \pm 6.54$ & $81.5 \pm 1.41$ \\
\hline
\end{tabular}


micrographs of drug-loaded microspheres are presented in Fig. 5 while the thermal curves of pure metformin and microspheres are shown in Fig. 6.

\section{In vitro dissolution studies and kinetic modelling of release profiles}

The result of in vitro dissolution studies of the metformin-loaded microspheres and marketed sustained release metformin tablets is presented in Fig. 7.

The correlation coefficients generated from the various release kinetic models are presented in Table 5. All the microsphere formulations fitted into the Korsmeyer-Peppas equation as they showed good linearity $\left(r^{2}=0.9970-\right.$ 0.9994) and slope between 0.928 and 1.210 .

\section{Discussion}

The yield $(28.48 \% \mathrm{w} / \mathrm{w})$ of gum obtained from Khaya senegalensis exudates was slightly higher than what was reported $(25.00 \%)$ by Olorunsola et al. [23]. This variation could be because of a difference in botanical source, processing parameters and environmental conditions. The higher yield could also be attributed to the concentration of the precipitating agent employed in the extraction.

The $\mathrm{pH}$ of the extracted khaya gum was in the acidic range, indicating its applicability in pharmaceutical preparations. Incorporation of basic excipients into drug formulations promotes oxidation of susceptible drugs [23]. Hence, acidic and neutral gums are more widely used for pharmaceutical formulations [23].

The microspheres prepared with the highest concentration of khaya gum had the highest particle size of
$1420 \pm 9.8 \mu \mathrm{m}$. The sizes of the formulations were statistically significant $(p<0.05)$. The swelling index of the microspheres (Table 4) increased as the concentration of khaya gum in the formulations increased. This might be attributed to the presence of pores and cavities present in the polymer as the concentration of khaya gum increased as indicated in the SEM micrographs of drugloaded microspheres (Fig. 5). However, there was statistically significant difference $(p<0.05)$ in swelling indices between microsphere formulations.

Entrapment efficiency is an essential parameter for assessing drug loading of microspheres. In addition, it indicates the extent to which the drug is embedded in the polymer network. In this study, the entrapment efficiency ranged from $65.6 \%$ to $81.5 \%$ in the microspheres made from khaya:sodium alginate gum polymer blends indicating that the presence of Khaya senegalensis gum in the formulations improved drug loading. Entrapment efficiency increased with an increase in concentration of khaya gum in the polymer network in the order $2: 3<9$ : $11<1: 1$. There was statistically significant difference $(p$ $<0.05$ ) in entrapment efficiencies between formulations.

Drug and excipients compatibility studies were studied by FTIR and DSC. FTIR technique is employed to study the changes in functional groups of host and guest molecules [29]. The study the FTIR spectrum of the microspheres (Fig. 4) showed that the major bands and peaks of metformin were retained. The additional bands and peaks that appeared in the spectrum of the microspheres might be attributed to the other excipients employed in the formulation.

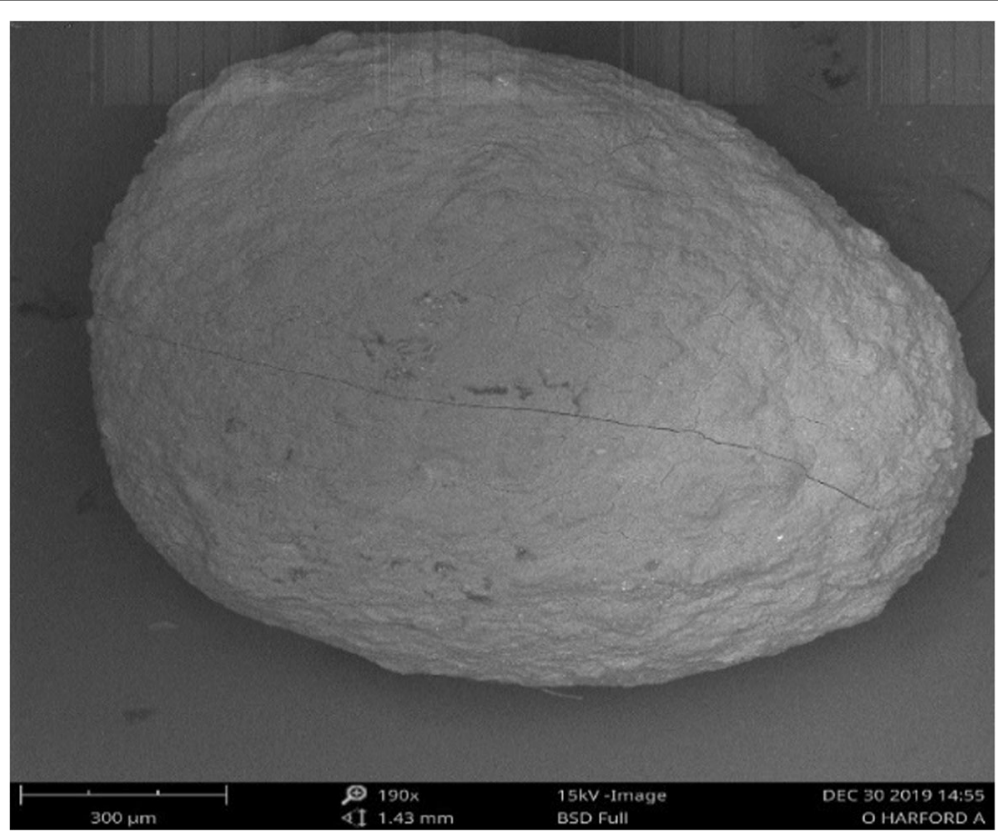

Fig. 5 SEM micrograph of metformin-loaded microsphere 

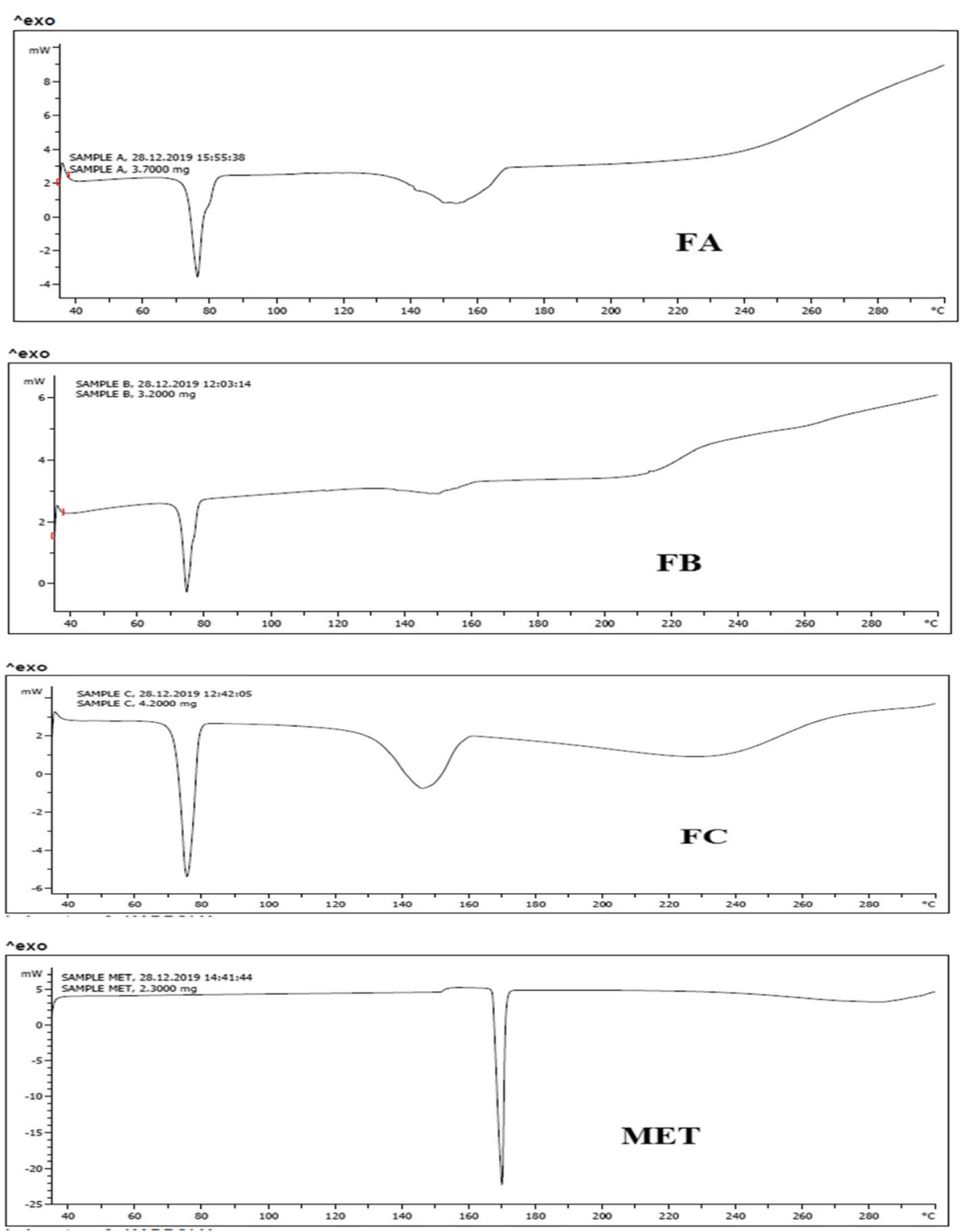

Fig. 6 Differential scanning calorimetry thermograms of pure metformin (MET) and microspheres (FA, FB, and FC)

The thermal curve of pure metformin (MET) exhibited an initial flat profile followed by a sharp endothermic peak at $170.27{ }^{\circ} \mathrm{C}$ (representing the melting point of metformin) and an associated fusion enthalpy of $661.29 \mathrm{~J} / \mathrm{g}$ indicating its crystalline state. The DSC thermograms of the microspheres showed a shift in the endothermic peak observed in metformin. The endothermic peaks of the microspheres (FA, FB, and FC) were observed at $77.11{ }^{\circ} \mathrm{C}, 75.51{ }^{\circ} \mathrm{C}$, and 77.98 ${ }^{\circ} \mathrm{C}$, respectively. Therefore, the thermal curve of the formulations and pure metformin maintained an initial flat profile but the incorporation of excipients in the formulations increased the melting points of the formulations. It has been observed that the differences in DSC thermograms do not always indicate incompatibilities between the samples [30].

The in vitro dissolution study showed that as the viscosity of the polymer matrix increased, there was a resultant resistance to polymer erosion and drug diffusion [31]. This indicates that the rate of release of drugs from microspheres is influenced by the drug/polymer ratio used in the formulation. The dissolution studies graph (Fig. 7) showed that formulations FA, FB, and FC released about $27 \%, 22 \%$, and $30 \%$ of metformin respectively after $2 \mathrm{~h}$ while the commercial brand sustained release metformin tablet (FM) (Panfor ${ }^{\circ}$ SR 500 mg, Mega Lifesciences Pty. Ltd., Thailand) released about $25 \%$. After $9 \mathrm{~h}$, the amount of drug released by the 


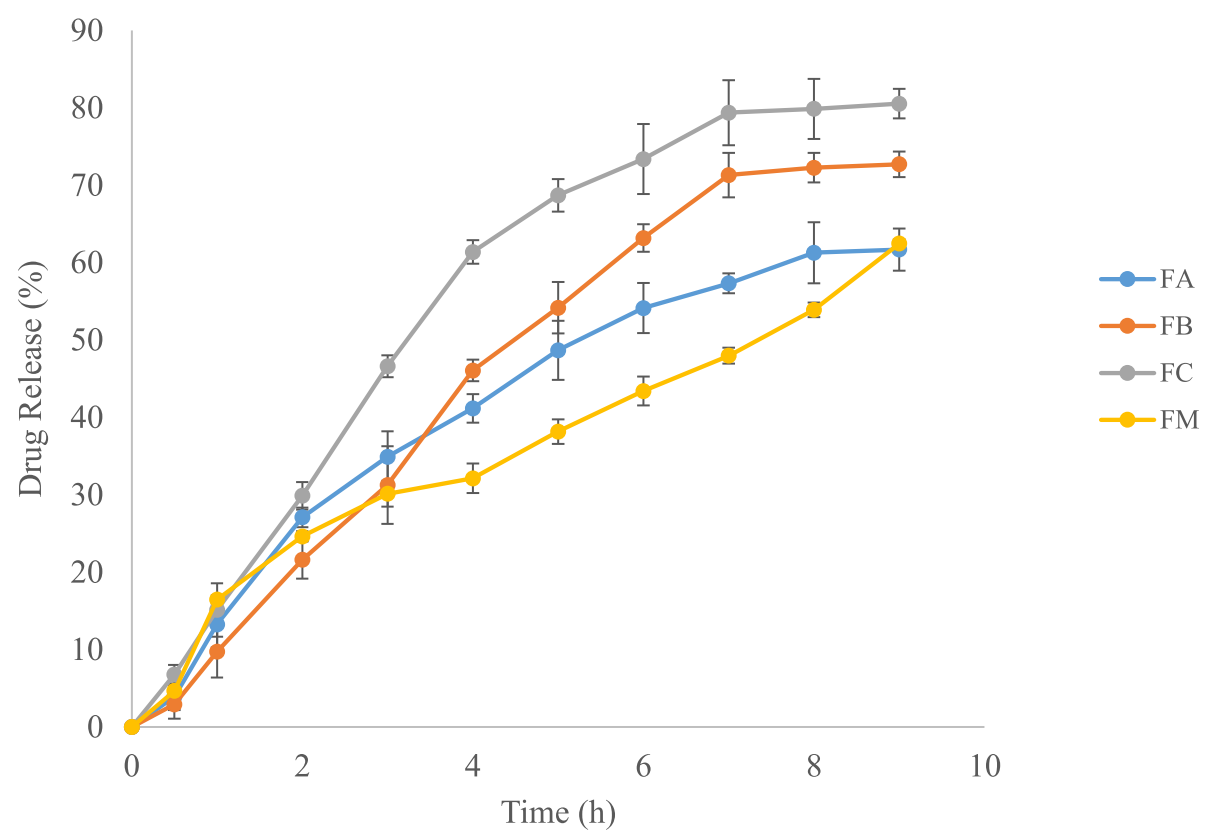

Fig. 7 In vitro release profile of microspheres and marketed metformin tablets

microspheres were about $62 \%, 73 \%$, and $80 \%$, respectively while the commercial brand metformin tablet released about 63\%. Although, the metformin-loaded microspheres and the commercial brand metformin tablet seemed to show similar release patterns, there were significant differences in their release properties. Apart from formulation FC, all the formulations released less than $5 \%$ of metformin at $30 \mathrm{~min}$. This is of great significant for formulations that are intended for sustained release. Burst release which has been designated as the release of more than $15 \%$ of the drug in the first $1 \mathrm{~h}$ is not desirable. In the study, the microspheres including the sustained release metformin tablet released approximately $15 \%$ of the drug or less which is desirable for sustained release formulations thus suggesting effective entrapment [26]. Among the three microsphere formulations, FA had more comparable release profile to that of the commercial brand metformin tablet (FM).

To determine the kinetics and mechanism of drug release from the microspheres, data obtained from in vitro release studies were fitted into kinetic models such as zero order, first order, Higuchi, and Korsmeyer-Peppas. The data were analysed by the regression coefficient method, and regression coefficient value $\left(r^{2}\right)$ of the microsphere formulations (Table 5). To confirm the release mechanism, the data were fitted into the Korsmeyer-Peppas equation as they showed good linearity $\left(r^{2}=0.9970-0.9994\right)$ with slope $(n)$ between 0.928 and 1.210) which indicates that the release of the drug followed a super case II transport system (occurs when sorption is controlled by stressinduced relaxations in swellable matrix systems) [32].

\section{Conclusion}

The extracted Khaya senegalensis gum had desirable pharmacopoeial and physicochemical properties and is a good candidate for potential applications as pharmaceutical excipient. The blend of the khaya gum and sodium alginate produced microspheres with controlled release properties. The ratio of drug to polymer influences drug release from the microspheres. Korsmeyer-Peppas was the best model to describe its release mechanism. Formulations containing 2:3 ratio of khaya gum and sodium alginate (FA) produced microspheres with comparable controlled release profiles to the commercial brand metformin tablet.

Table $\mathbf{5}$ In vitro release kinetic parameters of metformin from the microspheres

\begin{tabular}{|c|c|c|c|c|c|c|c|c|c|}
\hline \multirow[t]{2}{*}{ Formulation code } & \multicolumn{2}{|c|}{ Zero order } & \multicolumn{2}{|c|}{ First order } & \multicolumn{2}{|c|}{ Higuchi } & \multicolumn{3}{|c|}{ Korsmeyer-Peppas } \\
\hline & $r^{2}$ & $K$ & $\overline{r^{2}}$ & $K$ & $\overline{r^{2}}$ & $k$ & $\overline{r^{2}}$ & $k$ & $n$ \\
\hline$\overline{F A}$ & 0.9594 & 32.85 & 0.8308 & 0.11 & 0.9552 & 171.47 & 0.9970 & 1.53 & 0.928 \\
\hline $\mathrm{FB}$ & 0.9736 & 43.70 & 0.8657 & 0.13 & 0.9389 & 189.65 & 0.9990 & 1.70 & 1.210 \\
\hline FC & 0.9417 & 44.11 & 0.8553 & 0.11 & 0.9538 & 232.20 & 0.9994 & 1.50 & 1.020 \\
\hline
\end{tabular}




\section{Abbreviations}

AAS: Atomic absorption spectrophotometer; DSC: Differential scanning calorimetry; FA: Metformin (1\% w/v)-loaded microspheres prepared using 2\% $\mathrm{W} / \mathrm{v}$ blends of khaya gum and sodium alginate in the ratio of 2:3.

FB: Metformin ( $1 \% \mathrm{w} / \mathrm{v}$ )-loaded microspheres prepared using $2 \% \mathrm{w} / \mathrm{v}$ blends of khaya gum and sodium alginate in the ratio of 9:11; FC: Metformin (1\% w/ v)-loaded microspheres prepared using $2 \% \mathrm{w} / \mathrm{v}$ blends of khaya gum and sodium alginate in the ratio of 1:1; FTIR: Fourier-transform infrared spectroscopy; MET: Metformin; SEM: Scanning electron microscopy

\section{Acknowledgements}

The authors acknowledge Jopan Pharmaceutical Limited for providing metformin hydrochloride powder.

\section{Authors' contributions}

CPA conceived the study. Cll and MOO helped design and coordinate the study. $\mathrm{CHO}$ and SST carried out the experimental studies. CHO, CPA, MOO, and SST drafted the manuscript. All authors have read and approved the final manuscript.

\section{Funding}

No funding was obtained for the study.

\section{Availability of data and materials}

The datasets used and/or analysed during the current study are available from the corresponding author on reasonable request.

\section{Ethics approval and consent to participate}

Not applicable

\section{Consent for publication}

Not applicable

\section{Competing interests}

The authors declare that they have no competing interest.

Received: 3 July 2020 Accepted: 5 November 2020

Published online: 11 December 2020

\section{References}

1. Yaacob B, Amin MCIM, Hashim K, Bakar BA (2011) Optimization of reaction conditions for carboxymethylated sago starch. Iran Polymer J. 20(3):195-204

2. Prajapati VD, Jani GK, Moradiya NG, Randeria NP (2013) Pharmaceutical applications of various natural gums, mucilages and their modified forms. Carbohydr Polym 92(2):1685-1699. https://doi.org/10.1016/j.carbpol.2012.11.021

3. Bhaskar AD, Uttam KJ, Mahendrasingh A, Jayram MC, Bhanudas SR (2013) Plant exudates and mucilage as pharmaceutical excipients. J Adv Pharm Educ Res. 3(4):387-402

4. Odeku OA, Itiola OA (2003) Evaluation of the effects of khaya gum on the mechanical and release properties of paracetamol tablets. Drug Dev Ind Pharm 29(3):311-320. https://doi.org/10.1081/DDC-120018205

5. Ofori-Kwakye K, Adom ENN (2007) Mechanical properties of khaya and albizia films intended for pharmaceutical coating. J Ghana Sci Assoc. 9(2): 43-53

6. Kuevi DNO, Ayertey E, Barteis DA, Owusu FWA (2019) Evaluation of the disintegration properties of Khaya senegalensis gum using paracetamol tablets. Asian J Res Med Pharm Sci. 6(3):1-8. https://doi.org/10.9734/ AJRIMPS/2019/v6i330104

7. Odeku OA, Fell JT (2004) Evaluation of khaya gum as a directly compressible matrix system for controlled release. J Pharm Pharmacol 56(11):1365-1370. https://doi.org/10.1211/0022357044652

8. Schwimmer JB, Middleton MS, Deutsch R, Lavine JE (2005) A phase 2 clinical trial of metformin as a treatment for nondiabetic paediatric nonalcoholic steatohepatitis. Aliment Pharmacol Ther 21(7):871-879. https://doi. org/10.1111/j.1365-2036.2005.02420.x

9. Rouabhia S, Milic N, Abenavoli L (2014) Metformin in the treatment of non-alcoholic fatty liver disease: safety, efficacy and mechanism. Expert Rev. Gastroenterol.Hepatol 8(4):343-349. https:/doi.org/10.1586/17474124.2014.894880

10. Lord JM, Flight $\mathrm{H}$, Norman RJ (2003) Metformin in polycystic ovary syndrome: systematic review and meta-analysis. Br Med J 327:951-953. https://doi.org/10.1136/bmj.327.7421.951
11. Scheen AJ (1996) Clinical pharmacokinetics of metformin. Clin Pharmacokinet 30:359-371. https://doi.org/10.2165/00003088-19963005000003

12. Saini S, Kumar S, Choudhary M, Nitesh M, Budhwar V (2018) Microspheres as controlled drug delivery system: an updated review. Int J Pharm Sci Res 9(5):1760-1768. https://doi.org/10.13040/IJPSR.0975-8232.9(5).1760-68

13. Campos E, Branquinho J, Carreira AS, Carvalho A, Coimbra P, Ferreira P, Gil $\mathrm{MH}$ (2013) Designing polymeric microparticles for biomedical and industrial applications. Eur Polym J 49(8):2005-2021. https://doi.org/10.1016/j. eurpolymj.2013.04.033

14. Ofori-Kwakye K, Asantewaa Y, Kipo SL (2010) Physicochemical and binding properties of cashew tree gum in metronidazole tablet formulation. Int J Pharm Pharm Sci. 2(4):105-109

15. Auwal MS, Saka S, Mairiga IA, Sanda KA, Shuaibu A, Ibrahim A (2014) Preliminary phytochemical and elemental analysis of aqueous and fractionated pod extracts of Acacia nilotica (Thorn mimosa). Vet Res Forum. 5(2):95-100

16. Shah BN, Seth AK (2010) Textbook of Pharmacognosy and Phytochemistry, 1st edn. Elsevier Publishers, New Delhi, pp 189, 233-189, 234

17. Azubuike CP, Rodriguez H, Okhamafe AO, Rogers RD (2012) Physicochemical properties of maize cob cellulose powders reconstituted from ionic liquid solution. Cellulose 19:425-433. https://doi.org/10.1007/ s10570-011-9631-y

18. Ologunagba MO, Jain S, Thanki K, Suresh S, Furtado S, Azubuike CP, Silva OB (2017) Extraction and Characterisation of the Gum Exudate of Anacardium occidentale for its potential as an Excipient in Drug Delivery Systems. Trop J Nat Prod Res 1(2):76-83. https://doi.org/10.26538/tjnpr/v1i2.6

19. Sindhu R, Khatkar BS (2016) Morphological, pasting and thermal properties of common buckwheat (Fagopyrum Esculentum Moench) flour and starch. Int J Innov Res Adv Stud. 3(7):160-164

20. Yanli W, Wenyuan G, Xia L (2009) Carboxymethyl Chinese yam starch: synthesis, characterization, and influence of reaction parameters. Carbohydrate Res 344(13):1764-1769. https://doi.org/10.1016/j.carres.2009.06.014

21. Odeku OA, Okunlola A, Lamprecht A (2014) Formulation and in vitro evaluation of natural gum-based microbeads for delivery of ibuprofen. Trop J Pharm Res 13(10):1319-1326. https://doi.org/10.4314/tjpr.v13i10.17

22. Narkar M, Sher P, Pawar A (2010) Stomach specific controlled release gellan beads of acid soluble drug prepared by ionotropic gelation method. AAPS PharmSciTech 11(1):267-277. https://doi.org/10.1208/s12249-010-9384-1

23. Olorunsola EO, Bhatia PG, Tytler BA, Adikwu MU (2016) Thermochemical properties of hydrophilic polymers from cashew and khaya exudates and their applications on drug delivery. J Drug Delivery 7:Article ID 7496585. https://doi.org/10.1155/2016/7496585

24. Ajala TO, Akin-Ajani OD, Ihuoma-Chidi C, Odeku OA (2016) Chrysophyllum albidum mucilage as a binding agent in paracetamol tablet formulations. $J$ Pharm Invest 46(6):565-573. https://doi.org/10.1007/s40005-016-0266-8

25. British Pharmacopoeia (2009) British Pharmacopoeia Commission. The Stationery Office (TSO), London, United Kingdom.

26. Akin-Ajani OD, Ajala TO, Ikehin M (2019) Date mucilage as co-polymer in metformin-loaded microbeads for controlled release. J Excipients Food Chem. 10(1): 3-12.

27. United States Pharmacopoeia-National Formulary (USP 39 NF 34) (2016) The United States Pharmacopoeial Convention, Rockville, Maryland, United States

28. Wells Jl, Aulton ME (2007) Pharmaceutical preformulation. In: Aulton ME (ed) Aultons Pharmaceutics: Design and manufacture of medicines, 3rd edn. Churchill Livingstone publishers, London, pp 355-356

29. Manikandan M, Kannan K, Manavalan R (2013) Compatibility studies of camptothecin with various pharmaceutical excipients used in the development of nanoparticle formulation. Int J Pharm Sci. 5(4):315-321

30. Nep El, Conway BR (2012) Preformulation studies on grewia gum as a formulation excipient. J Ther Anal Calorim 108(1):197-205. https://doi.org/ 10.1007/s10973-011-1782-4

31. Lee PI, Peppas NA (1987) Prediction of polymer dissolution in swellable controlled-release systems. J Controlled Rel 6(1):207-215. https://doi.org/10. 1016/0168-3659(87)90077-0

32. Peppas NA, Sahlin JJ (1989) A simple equation for the description of solute release. III. Coupling of diffusion and relaxation. Int J Pharm 57(2):169-172. https://doi.org/10.1016/0378-5173(89)90306-2

\section{Publisher's Note}

Springer Nature remains neutral with regard to jurisdictional claims in published maps and institutional affiliations. 